\title{
Study of pregnancy outcome in relation to first trimester body mass index
}

\author{
Prachi Srivastava, Hema Verma*
}

Department of Obstetrics and Gynecology, T. S. Misra Medical College and Hospital, Lucknow, Uttar Pradesh, India

Received: 09 September 2019

Accepted: 01 October 2019

\section{*Correspondence:}

Dr. Hema Verma,

E-mail: hemaverma6943@gmail.com

Copyright: (C) the author(s), publisher and licensee Medip Academy. This is an open-access article distributed under the terms of the Creative Commons Attribution Non-Commercial License, which permits unrestricted non-commercial use, distribution, and reproduction in any medium, provided the original work is properly cited.

\begin{abstract}
Background: Early pregnancy body mass index (BMI) plays an important role in pregnancy outcome. Women with either low or high BMI have an adverse pregnancy outcome. American college of obstetricians and gynecologists (ACOG) recommends calculation of BMI for all pregnant women at their first visit. This study was conducted to assess maternal and fetal outcome in women based on first trimester BMI.

Methods: This was a prospective observational study conducted in Department of Obstetrics and Gynecology of T. S. Misra Medical college and hospital, Lucknow from January 2018 to January 2019. Patients with singleton pregnancy booked in first trimester were included while women with multiple pregnancy, pre-existing medical conditions were excluded from the study. Proper history taking and examination was done, and patients divided into five groups as per guidelines of WHO and National Institute of Health Guidelines. Patients were followed up during entire antenatal period. Any maternal and fetal complications were recorded.

Results: Incidence of anemia and intrauterine growth restriction (IUGR) was seen more in underweight patients. Postpartum hemorrhage (PIH), gestational diabetes and macrosomia was associated more with patients who were overweight or obese. There was significantly more incidence of lower (uterine) segment caesarean section (LSCS), instrumental delivery, wound sepsis and PPH in patients with higher BMI. SGA babies were seen more in patients with low BMI while large for gestational age (LGA) babies were seen more in patients with high BMI. More neonatal intensive care unit (NICU) admissions were seen in patients with low or high BMI.

Conclusions: Complications during pregnancy and adverse pregnancy and neonatal complication was seen significantly more in patients on either side of BMI (underweight and obese). Hence it can be concluded that BMI of a patient directly affects pregnancy outcome.
\end{abstract}

Keywords: Anemia, Body mass index, Intrauterine growth restriction, Pregnancy induced hypertention, gestational diabetes, Postpartum hemorrhage

\section{INTRODUCTION}

Early pregnancy BMI plays an important role in pregnancy outcome. Women with low BMI or high BMI both have an adverse pregnancy outcome. ${ }^{1}$

BMI is calculated by dividing weight of person in kilogram by the square of their height in metres. $\left(\mathrm{BMI}=\mathrm{kg} / \mathrm{m}^{2}\right)$.
Women with higher BMI are at increased risk of gestational diabetes, pregnancy induced hypertension, postpartum hemorrhage, caesarean section, shoulder dystocia, difficult labor, macrosomic babies, instrumental delivery, birth asphyxia and postpartum hemorrhage. ${ }^{2}$

Women with lower BMI are at increased risk of preterm deliveries, low birth weight, anemia and prematurity. ${ }^{3}$ 
So maternal BMI and maternal nutrition needs to be given adequate importance in pregnancy and should be a routine part of antenatal assessment to ensure good maternal and neonatal outcome. ACOG recommends calculation of BMI for all pregnant women at their first visit. $^{4}$

Gestational weight gain is a modifiable risk factor in pregnancy and thus, giving it adequate importance during antenatal follow up of patient can result in better maternal and fetal outcome. Institute of medicines has brought forth recommendations for weight gain in pregnancy. ${ }^{5}$

This study was thus conducted with the aim to assess maternal and fetal outcome in patients with high as well as low BMI to ensure more careful monitoring in such patients to ensure good maternal and fetal outcome.

\section{METHODS}

This was a prospective observational study conducted in Department of Obstetrics and Gynecology of T. S. Mishra Medical College and Hospital, Lucknow for a period of 1 years from January 2018 to January 2019.

Inclusion criteria considered were patients who booked in first trimester of pregnancy with singleton pregnancy. Women with multiple pregnancy, pre-existing medical conditions like diabetes, chronic hypertension, heart disease, hypothyroidism, were excluded from the study.

Patients who satisfied these criteria were included in the study and proper history taking and examination was done. Patients were divided into 4 groups as per guidelines of WHO and national institute of Health Guidelines (Table 1). Patients were followed up carefully during entire antenatal period. Record of weight gain was done. Any antenatal, postnatal and maternal and fetal complications were recorded.

Table 1: Categorization of patients on basis of BMI.

\begin{tabular}{|ll|}
\hline Group & BMI \\
\hline Group I (underweight) & $\begin{array}{l}\text { Less than or equal to } \\
19.9 \mathrm{~kg} / \mathrm{m}^{2}\end{array}$ \\
\hline Group II (normal) & BMI $: 20-24.9 \mathrm{~kg} / \mathrm{m}^{2}$ \\
\hline Group III (overweight) & BMI: $25-29.9 \mathrm{~kg} / \mathrm{m}^{2}$ \\
\hline Group IV (obese) & BMI: $30-34.9 \mathrm{~kg} / \mathrm{m}^{2}$ \\
\hline Group V (morbidly obese) & BMI: $>35 \mathrm{~kg} / \mathrm{m}^{2}$ \\
\hline
\end{tabular}

\section{Statistical analysis}

Statistical test was performed by using Mann Whitney test, ANOVA and chi square analysis. $\mathrm{P}$ value less than 0.05 was considered as significant.

\section{RESULTS}

Based on inclusion and exclusion criteria, 200 patients were included in the study. The patients were comparable for their demographic profile. Based on BMI, patients were divided into five groups. Distribution of patients in different groups is shown in Table 2.

Table 2: Distribution of patients according to BMI.

\begin{tabular}{|llll|}
\hline Group & BMI & $\begin{array}{l}\text { No. of } \\
\text { women }\end{array}$ & $\begin{array}{l}\% \text { of } \\
\text { women }\end{array}$ \\
\hline I-underweight & $<19.9$ & 33 & $16.5 \%$ \\
\hline II-normal weight & $20-24.9$ & 95 & $47.5 \%$ \\
\hline III-overweight & $25-29.9$ & 45 & $22.5 \%$ \\
\hline IV-obese & $30-34.9$ & 27 & $13.5 \%$ \\
\hline V- morbidly obese & $>35$ & 0 & 0 \\
\hline
\end{tabular}

Table 3: Comparison of complications during antenatal period based on BMI.

\begin{tabular}{|c|c|c|c|c|c|}
\hline BMI Group & I $(\mathrm{n}=33)$ & II (n=95) & III $(n=45)$ & IV (n=27) & P-value \\
\hline $\mathrm{PIH}$ & $1(3.03 \%)$ & $1(1.05 \%)$ & $4(8.88 \%)$ & $4(14.81 \%)$ & $<0.01$ \\
\hline Gestational diabetes & $1(3.03 \%)$ & $11(11.57 \%)$ & $12(26.67 \%)$ & $9(33.33 \%)$ & $<0.01$ \\
\hline Anemia & $7(21.21 \%)$ & $9(9.47 \%)$ & $5(11.11 \%)$ & $1(3.70 \%)$ & $<0.05$ \\
\hline IUGR & $12(37.3 \%)$ & $11(11.59 \%)$ & $6(13.33 \%)$ & $6(22.22 \%)$ & $<0.05$ \\
\hline macrosomia & $0(0 \%)$ & $1(1.05 \%)$ & $2(2.25 \%)$ & $4(14.81 \%)$ & $<0.01$ \\
\hline
\end{tabular}

The patients were compared on basis of presence of complications during antenatal period. complications studied were PIH, anemia, gestational diabetes, IUGR and macrosomia. It was seen that incidence of anemia and IUGR was more associated with underweight patients while PIH, gestational diabetes and macrosomia was associated more with patients who were overweight or obese. Patients with normal BMI had lower incidence of these complications. The occurrence of these complications was significantly related to BMI (Table 3).

There was more incidence of LSCS and instrumental delivery in patients with higher BMI. These patients also had increased incidence of wound sepsis and PPH. The difference was found to be statistically significant (Table 4). 
Table 4: Comparison of mode of delivery and complications in early postpartum period.

\begin{tabular}{|llll|ll|}
\hline Method of delivery & I $(\mathbf{n}=\mathbf{3 3})$ & II $(\mathbf{n}=\mathbf{9 5})$ & III $(\mathbf{n}=\mathbf{4 5})$ & IV $(\mathbf{n = 2 7})$ & P-value \\
\hline LSCS & $10(31.25 \%)$ & $28(29.78 \%)$ & $24(54.54 \%)$ & $11(42.3 \%)$ & $<0.05$ \\
\hline Instrumental delivery & $2(6.25 \%)$ & $5(5.26 \%)$ & $3(6.66 \%)$ & $4(15.38 \%)$ & $<0.01$ \\
\hline Normal vaginal delivery & $18(54.54 \%)$ & $54(56.84 \%)$ & $22(48.88 \%)$ & $12(44.44 \%)$ & $<0.05$ \\
\hline $\begin{array}{l}\text { Complications in early } \\
\text { postpartum period }\end{array}$ & $\mathbf{I}(\mathbf{n = 3 3})$ & $\mathbf{I I}(\mathbf{n = 9 5})$ & $\mathbf{I I I}(\mathbf{n}=\mathbf{4 5})$ & $\mathbf{I V}(\mathbf{n = 2 7})$ & P-value \\
\hline PPH & $1(3.03 \%)$ & $2(2.10 \%)$ & $3(6.6 \%)$ & $2(7.4 \%)$ & $<0.05$ \\
\hline Wound sepsis & $2(7.4 \%)$ & $1(1.05 \%)$ & $1(2.22 \%)$ & $2(7.4 \%)$ & $<0.05$ \\
\hline
\end{tabular}

Table 5: Comparison of neonatal outcome.

\begin{tabular}{|llllll|}
\hline Neonatal outcome & I $(\mathrm{n}=\mathbf{3 3})$ & II $(\mathrm{n}=\mathbf{9 5})$ & III $(\mathrm{n}=\mathbf{4 5})$ & IV $(\mathrm{n}=\mathbf{2 7})$ & P-value \\
\hline SGA & $12(36.36 \%)$ & $11(11.57 \%)$ & $6(13.33 \%)$ & $6(22.22 \%)$ & $<0.05$ \\
\hline LGA & $0(0 \%)$ & $1(1.05 \%)$ & $2(4.44 \%)$ & $4(14.8 \%)$ & $<0.01$ \\
\hline NICU admission & $2(6.06 \%)$ & $1(1.05 \%)$ & $3(6.67 \%)$ & $2(7.4 \%)$ & $<0.05$ \\
\hline Perinatal death & 0 & 0 & 0 & 0 & - \\
\hline
\end{tabular}

SGA babies were seen more in patients with low BMI while LGA babies were seen more in patients with high BMI. More babies in patients with low BMI or high BMI required NICU admissions. The difference was statistically significant (Table 5). No perinatal deaths occurred in any of the groups.

\section{DISCUSSION}

This was a prospective observational study conducted in Department of Obstetrics and Gynecology of T. S. Misra Medical College and Hospital, Lucknow from January 2018 to January 2019.

Total of 200 pregnant women in first trimesters of pregnancy were included in the study based on inclusion and exclusion criteria and studied for various antenatal, intranatal and postnatal complications.

Patients were comparable for their demographic profile.

In our study it was seen that in antenatal period, incidence of anemia and IUGR were more common in patients who were underweight [lower BMI (group 1)] while $\mathrm{PIH}$, gestational diabetes and macrosomia were more seen in patients with overweight and obese women (group III and IV). This finding was consistent with studies by Sahu MT et al, who showed that anemia and low birthweight was significantly present among lean women while obese women had a significant risk for gestational diabetes, pre-eclampsia, cesarean delivery and macrosomia. ${ }^{2}$ Verma $\mathrm{A}$ et al, showed that in the underweight group, the incidences of anaemia and growth retardation were more, while the overweight and the obese women had a higher risk for PIH and gestational diabetes, Bhattacharya $\mathrm{S}$ et al, showed that morbidly obese women faced the highest risk of pre-eclampsia and underweight women the lowest. ${ }^{3,6}$ Fujiwara $\mathrm{K}$ et al, showed that the higher the pre-pregnancy BMI, the higher the incidences of pregnancy-induced hypertension, gestational diabetes mellitus. ${ }^{7}$ Takai IU et al, concluded that Maternal outcomes mostly associated with obesity and overweight were hypertensive disorders in pregnancy (42.0\%), gestational diabetes mellitus (41.3\%). ${ }^{8} \mathrm{~A}$ metaanalysis of PIH associated with maternal BMI showed that risk of pre-eclampsia doubled with $5-7 \mathrm{~kg} / \mathrm{m}^{2}$ increase in BMI. ${ }^{9}$

The rate of caesarean section and instrumental vaginal delivery was associated more with higher BMI. Due to increased rate of cesarean section, these patients had higher rate of perioperative morbidity including anaesthetic problems, infections and prolonged hospitalization. We found an increased rate of wound sepsis in patients who were underweight or obese, patients with higher BMI showed an increased rate of PPH. Similar findings were seen in studies by Verma A et al, who showed higher incidence of LSCS and wound sepsis in overweight and obese women. ${ }^{3}$ Sahu MT et al, showed significantly higher incidence of cesarean delivery and macrosomia in overweight and obese women. ${ }^{2}$ Bhattacharya $\mathrm{S}$ et al, also demonsrated higher incidence of cesarean section and PPH in obese women while such incidences were less in underweight and normal women and also comparable. ${ }^{6}$ Fujikara $\mathrm{K}$ et al, also showed higher incidence of cesarean section and PPH in women with higher BMI. ${ }^{7}$ Takai IU et al, also showed higher incidence of cesarean section in overweight and obese women but showed more incidence of PPH in normal weight women rather than in overweight or underweight women but attributed this to probable less monitoring of labor in normal weight women as compared to underweight, overweight or obese. $^{8}$ Bainco et al, however found no difference in incidence of PPH in relation to BMI. ${ }^{10}$ 
The risk of low birth weight was seen more in patients who were underweight and incidence of large for date infants was more in overweight and obese women. This result was consistent with other studies by Verma A et al, Sahu MT et al, Bhattacharya S et al, Fujikara K et al and O'Brien TE et al. 2,3,6,7,9 Studies by Sebire NJ et al and Weiss JL et al has shown that obese women have 18-26\% chances of delivering large for date infants as compared to women with normal BMI. ${ }^{11,12}$ NICU admissions were seen more in underweight group due to IUGR and in overweight and obese group probably due to high incidence of macrosomia and maternal diabetes.

\section{CONCLUSION}

Complications in pregnancy in antenatal period, during labor, postnatal period and adverse neonatal outcome was seen significantly more in patients on either side of BMI (underweight and obese). We did not have morbidly obese group in our study.

Hence it can be concluded that BMI of a patient directly affects pregnancy outcome.

It is thus advised to record BMI of all patients at their first visit and patients' weight be recorded at every consequent visit to ensure proper BMI and thus reduction of complications during pregnancy and ensuring a better neonatal outcome.

\section{Funding: No funding sources}

Conflict of interest: None declared

Ethical approval: The study was approved by the Institutional Ethics Committee

\section{REFERENCES}

1. International Institute for Population Sciences (IIPS) and macro international 2007. National Family Health Survey (NFHS-3), 2005-06. India. Mumbai: IIPS. 2006:1.

2. Sahu MT, Agarwal A, Das V, Pandey A. Impact of maternal body mass index on obstetric outcome. J Obstet Gynaecol Res. 2007;33(5):655-9.

3. Verma A, Lalit S. Maternal body mass index and pregnanacy outcome. J Clin Diag Res. 2012;6(9):1531-3.
4. American College of Obstetricians and Gynecologists. ACOG Committee opinion number 315, September 2005. Obesity in Pregnancy, Obstet Gynaecol. 2005;106(3):671-5.

5. Institute of Medicine (US) Committee on Nutritional Status During Pregnancy and Lactation. Nutrition During Pregnancy: Part I Weight Gain: Part II Nutrient Supplements. Washington (DC): National Academies Press (US); 1990. Available at: https://www.ncbi.nlm.nih.gov/books/NBK235228/.

6. Bhattacharya S, Campbell DM, Liston WA. Effect of body mass index on pregnancy outcome in nulliparous women delivering singleton babies. BMC Public Health. 2007;7:168.

7. Fujiwara K, Sakamaki A, Hirhara F. Pregnanacy outcomes based on pre pregnancy body mass index in Japanese women. PLOS ONE. 2016;11(6):e0157081.

8. Takai IU, Omeje IJ, Kevaybura AS. First trimester body mass index and pregnancy outcomes: A 3 year retrospective study from low resource setting. Arch Int Surg. 2017;7:41-7.

9. O'Brien TE, Ray JG, Chan WS. Maternal body mass index and risk of pre-eclampsia. A systemic review. Epidemiol. 2003;14:368-74.

10. Bainco AT, Smilex SW, Davis Y, Lapsinki R, Lockwood CJ. Pregnancy outcome and weight gain recommendations for morbidly obese woman. Obstet Gynaecol. 1998;91(1):97-102.

11. Sebire NJ, Jolly M, Harris JP, Wadsworth J, Joffe M, Beard RW, et al. Maternal obesity and pregnancy outcome: a study of 287213 pregnancies in London. Int J Obs. 2001;25:1175-82.

12. Weiss JL, Malone FD, Emig D, Ball RH, Nyberg DA, Comstock CH. Obesity, obstetric complications and cesarean delivery rate: a population-based screening study. Am J Obstet Gynaecol. 2004;190:1091-7.

Cite this article as: Srivastava $\mathrm{P}$, Verma $\mathrm{H}$. Study of pregnancy outcome in relation to first trimester body mass index. Int J Reprod Contracept Obstet Gynecol 2019;8:4187-90. 